\title{
Clinical Analysis of Primary Eosinophilic Esophagitis
}

\author{
Jung Ho Lee, ${ }^{1}$ Moo Jung Kim, ${ }^{1}$ Jie-Hyun Kim, ${ }^{1}$ Young Hoon Youn, ${ }^{1}$ Nayoung Kim, ${ }^{2}$ Young-Tae Bak, ${ }^{3}$ Yunju Jo ${ }^{4}$ and \\ Hyojin Park ${ }^{1 *}$
}

${ }^{1}$ Department of Internal Medicine, Gangnam Severance Hospital, Yonsei University College of Medicine, Seoul, Korea; ${ }^{2}$ Department of Internal Medicine, Seoul National University Bundang Hospital, Seongnam, Gyeonggi-do, Korea; ${ }^{3}$ Department of Internal Medicine, Korea University Guro Hospital, Korea University College of Medicine, Seoul, Korea; and ${ }^{4}$ Department of Internal Medicine, Eulji University College of Medicine, Seoul, Korea

\section{Background/Aims}

Eosinophilic esophagitis (EOE) is a chronic inflammatory disorder of the esophagus. Similar to asthma, EoE can induce irreversible structural changes in the esophagus as a result of chronic and persistent eosinophilic inflammation. The aim of this study was to analyse changes in symptoms, eosinophil counts and endoscopic findings after treatment.

\section{Methods}

Nine patients with EoE (6 men and 3 women; mean age, 36.44 years) were diagnosed with EoE based on typical symptoms, endoscopic abnormalities and infiltration of the esophageal epithelium with $\geq 15$ eosinophils/high-power field. The average endoscopic follow-up period was 10 months, ranging from 1 to 25 months. Symptoms and endoscopic and pathological findings at initial observation and follow-up were evaluated.

\section{Results}

Seven of the 9 patients had dysphagia symptoms, which improved in 4 of 6 patients who were treated with proton pump inhibitor. Two patients were unresponsive to proton pump inhibitor and another 2 patients were treated with corticosteroid, which led to symptomatic relief. In 8 patients, esophageal eosinophilia was improved histologically at follow-up after treatment. Six of the 9 patients had typical endoscopic findings of EoE at initial examination. Despite treatment, these findings remained in 5 of the 6 patients at follow-up endoscopy.

\section{Conclusions}

After treatment, the symptoms and eosinophil counts were temporarily improved, but the endoscopic findings of EoE were generally not improved. This indicates that deformity of esophageal structure due to eosinophilic inflammation might be irreversible despite proper management.

\section{(J Neurogastroenterol Motil 2013;19:204-209)}

Key Words

Endoscopy; Eosinophilic esophagitis; Inflammation

Received: October 8, 2012 Revised: March 12, 2013 Accepted: March 18, 2013

(c) This is an Open Access article distributed under the terms of the Creative Commons Attribution Non-Commercial License (http://creativecommons. org/licenses/by-nc/3.0) which permits unrestricted non-commercial use, distribution, and reproduction in any medium, provided the original work is properly cited.

*Correspondence: Hyojin Park, MD, PhD

Department of Internal Medicine, Gangnam Severance Hospital, Yonsei University College of Medicine, 211, Eonjuro, Gangnam-gu, Seoul 135-720, Korea

Tel: +82-2-2019-3318, Fax: +82-2-3463-3882, E-mail: HJPARK21@yuhs.ac

Financial support: None.

Conflicts of interest: None.

Author contributions: Jung Ho Lee analyzed data and wrote the manuscript. Moo Jung Kim revised the manuscript by checking the contents and English. Jie-Hyun Kim revised the manuscript and advised design of study. Young Hoon Youn, Nayoung Kim, Young-Tae Bak and Yunju Jo collected and interpreted data. Hyojin Park designed this study and supervised preparing manuscript. 


\section{Introduction}

Primary eosinophilic esophagitis (EoE) is a chronic inflammatory disorder associated with eosinophilic infiltration of the esophagus. The first case was described by Landres et $\mathrm{al}^{1}$ more than 30 years ago, and in 1993 Attwood et $\mathrm{al}^{2}$ reported the first study of 12 adult patients with esophageal eosinophilia with dysphagia. Recently, EoE has been increasingly recognized and actively investigated in Western countries. However, in Asian populations there are very few reported adult cases of EoE and only limited studies have been performed. In our hospital, EoE has been actively studied and clinical implications ${ }^{3}$ and clinicopathological features ${ }^{4}$ have been reported.

In adults, EoE is predominantly observed in male patients and the average age of onset is between the twenties and forties. Dysphagia with solid food impaction is the most common symptom in adult patients with EoE. Heartburn or chest pain has also been reported. ${ }^{5,6}$ In some cases typical symptoms persist despite prolonged treatment with proton pump inhibitor (PPI) or normal $\mathrm{pH}$ monitoring of the distal esophagus. ${ }^{7,8}$ EoE with typical symptoms and endoscopic findings is confirmed by a high degree of esophageal eosinophilic infiltration ( $\geq 15 /$ high power field [HPF] $)^{8}{ }^{8}$

A recent study from Japan ${ }^{9}$ reported symptoms, endoscopic and pathological findings, and treatment outcomes for 12 patients with EoE. Seven patients treated with PPI or topical steroid therapy showed symptomatic and histological improvements. However, treatment outcomes were not evaluated in 5 patients and only 2 patients, who were treated with oral fluticasone propionate as topical steroid therapy, showed improved endoscopic findings at follow-up.

Another study ${ }^{10}$ investigated the natural history of 30 adult patients with EoE during a mean 7.2-year follow-up period and reported that endoscopic findings were not significantly changed at follow-up. Esophageal eosinophilic infiltration persisted in all symptomatic patients, but cell numbers decreased significantly. The authors suggested that chronic inflammation may lead to irreversible structural changes in the esophagus with a concomitant risk of impaired function.

Despite an increased understanding of inflammatory pathogenesis and possible irreversible structural changes in the esophagus, changes in endoscopic findings following treatment of EoE are not clearly defined. The aim of our study was to analyze changes in symptoms, eosinophil counts, and endoscopic findings after treatment in patients with EoE.

\section{Materials and Methods}

We reviewed patients with clinically, endoscopically, and histologically confirmed diagnoses of EoE, retrospectively. The diagnostic confirmation for EoE was defined as a peak of $\geq 15$ eosinophils/HPF. Among patients with confirmed EoE, those who did not undergo endoscopic examination at follow-up were excluded. Consequently, 9 patients with EoE, who were diagnosed at 4 university hospitals between June 2006 and December 2011, were included. Before proceeding the study, we obtained the permission from the Institutional Review Board of Gangnam Severance Hospital, Yonsei University College of Medicine.

We considered baseline characteristics of sex, age, and body mass index (BMI). Allergic history included food allergy, allergic rhinitis, allergic dermatitis and asthma. Serum haematologic and chemistry sampling was performed and analysed.

Analysed symptoms were dysphagia, heartburn, chest pain, and sore throat. We assessed dysphagia intensity using the following scoring system ${ }^{10}: 1=$ swallowing unhindered and without pain, 2 = slight retching disappearing spontaneously (spontaneous anterograde removal), 3 = short periods of obstruction necessitating intervention such as drinking, deep breathing or retching (induced anterograde removal), 4 = longer-lasting obstruction only removable by vomiting (forced retrograde removal) and $5=$ continuous complete obstruction not removable by the patient (requiring endoscopic intervention).

We performed endoscopic examinations at first examination and follow-up. Typical findings were linear furrow, corrugated ring, stricture, friability, and white plaque. Endoscopic findings were classified using the following scoring system ${ }^{10}: 1=$ absent, $2=$ minimal (fine nodule or fine whitish reticular structure or linear furrow), 3 = moderate (bright-whitish scale-like, plaque-like structure or corrugated ring) and $4=$ severe (mucosal lesion or fixed stenosis).

Reflux oesophagitis was also confirmed and graded. Endoscopic esophageal biopsy specimens were obtained from mid or lower esophagus of all patients, regardless of their symptoms and endoscopic findings. Tissue samples from endoscopic biopsy were analysed for eosinophil counts and other histologic findings at first examination and follow-up.

Treatment for EoE was PPI and/or inhaled or oral corticosteroid (fluticasone propionate) for 4-8 weeks. The treatment responses of pathologic condition (eosinophilic counts) were classified by the following degree of the result: persistence $=\geq$ 
$15 / \mathrm{HPF}$, decrease $=4-14 / \mathrm{HPF}$ and disappearance $=<4 / \mathrm{HPF}$.

\section{Results}

Nine patients ( 6 men and 3 women) with EoE that was confirmed histologically by endoscopic biopsy were enrolled in this study. The age, gender, symptoms, allergic state and dysphagia intensity of enrolled patients are summarised in Table 1 and fol-

Table 1. Characteristics of Subjects

\begin{tabular}{|c|c|c|c|c|}
\hline Case No. & Age (yr) & Gender & Symptom & Allergic condition \\
\hline 1 & 48 & M & Dysphagia & Yes (unknown factor) \\
\hline 2 & 24 & M & No symptom & Yes (food) \\
\hline 3 & 19 & M & $\begin{array}{l}\text { Dysphagia } \\
\text { Sore throat }\end{array}$ & $\begin{array}{l}\text { Asthma } \\
\text { Allergic rhinitis }\end{array}$ \\
\hline 4 & 60 & M & Dysphagia & $\mathrm{No}$ \\
\hline 5 & 58 & $\mathrm{~F}$ & $\begin{array}{l}\text { Dysphagia } \\
\text { Heartburn }\end{array}$ & No \\
\hline 6 & 8 & $\mathrm{~F}$ & $\begin{array}{l}\text { Dysphagia } \\
\text { Vomiting }\end{array}$ & No \\
\hline 7 & 49 & $\mathrm{~F}$ & Sore throat & No \\
\hline 8 & 28 & M & Dysphagia & $\mathrm{No}$ \\
\hline 9 & 34 & M & Dysphagia & Yes (food) \\
\hline
\end{tabular}

low-up results of endoscopic and histological findings, dysphagia score, concomitant reflux oesophagitis, and treatment outcomes are summarized in Table 2. The mean age of patients was 36.4 years (range 8-60 years). Five of the patients had allergic conditions such as food allergy, allergic rhinitis, or asthma. Among the nine patients, dysphagia symptoms were present in 7 (77.7\%), sore throat in $2(22.2 \%)$ and heartburn in $1(11.1 \%)$. The dysphagia intensity score was 4 in 1 patient, 3 in 3, 2 in 3, and 1 (normal) in 2. The mean duration of follow-up endoscopy was 8 months (range 1-25 months). Two of 3 patients with dysphagia who were treated with PPI alone showed improvement in symptoms. Two patients who had not been responsive to PPI and other 2 patients (total 4 patients) were treated with corticosteroid, which led to symptomatic relief or reduction of eosinophile counts. The overall dysphagia intensity increased from one point to two points in 1 patient, was persistent and stable in 2 , and decreased in 6. Concomitant reflux esophagitis was observed in 2 patients, but was not evident on follow-up endoscopy. In 8 of the 9 patients, esophageal eosinophilia was histologically improved after treatment at follow-up. Their eosinophilic count were became disappeared $(<4 / \mathrm{HPF})$ or decreased $(<15 / \mathrm{HPF})$. Six of the 9 patients had typical endoscopic findings of $\mathrm{EoE}$ at initial diagnosis. Despite treatment, 5 of the 6 patients still had typical

Table 2. Follow-up Results of Endoscopic and Histologic Findings, Dysphagia Score, Reflux Esophagitis and Treatment Outcomes

\begin{tabular}{|c|c|c|c|c|c|c|c|c|c|}
\hline \multirow[b]{2}{*}{$\begin{array}{l}\text { Case } \\
\text { No. }\end{array}$} & \multicolumn{3}{|c|}{ Initial } & \multirow{2}{*}{$\begin{array}{c}\text { Interval of } \\
\text { follow-up } \\
\text { endoscopy } \\
\text { (mo) }\end{array}$} & \multicolumn{5}{|c|}{ Treatment outcomes } \\
\hline & $\begin{array}{l}\text { Endoscopic } \\
\text { finding }\end{array}$ & $\begin{array}{c}\text { Dysphagia } \\
\text { score }\end{array}$ & $\begin{array}{c}\text { Reflux } \\
\text { esophagitis }\end{array}$ & & $\begin{array}{c}\text { Therapeutic } \\
\text { agent }\end{array}$ & $\begin{array}{l}\text { Esophageal } \\
\text { eosinophilia }\end{array}$ & Endoscopic alteration & $\begin{array}{l}\text { Dysphagia } \\
\text { score }\end{array}$ & $\begin{array}{c}\text { Reflux } \\
\text { esophagitis }\end{array}$ \\
\hline 1 & $\begin{array}{l}\text { Linear furrow } \\
\text { Concentric rings }\end{array}$ & 3 & $(-)$ & 3 & PPI & Disappearance & No change & 1 & $(-)$ \\
\hline 2 & $\begin{array}{l}\text { Linear furrow } \\
\text { Concentric rings }\end{array}$ & 1 & $(+)$ & 3 & PPI & Disappearance & No change & 1 & $(-)$ \\
\hline 3 & Linear furrow & 2 & $(-)$ & 6 & PPI & Disappearance & $\begin{array}{l}\text { Aggravation } \\
\text { (white plaque) }\end{array}$ & 2 & $(-)$ \\
\hline 4 & Linear furrow & 3 & $(-)$ & 6 & No treatment & Disappearance & Partial improvement & 1 & $(-)$ \\
\hline 5 & $\begin{array}{l}\text { Linear furrow } \\
\text { Concentric rings }\end{array}$ & 2 & $(-)$ & 25 & $\begin{array}{l}\text { PPI (first) } \\
\text { Oral steroid (second) }\end{array}$ & Disappearance & No change & 1 & $(-)$ \\
\hline 6 & Normal & 4 & $(+)$ & 1 & Oral steroid & Disappearance & Normal & 1 & $(-)$ \\
\hline 7 & $\begin{array}{l}\text { Linear furrow } \\
\text { Concentric rings }\end{array}$ & 1 & $(-)$ & 21 & Oral steroid & Disappearance & Partial improvement & 2 & $(-)$ \\
\hline 8 & Nodularity & 2 & $(-)$ & 2 & PPI & Decrease & Normal & 1 & $(-)$ \\
\hline 9 & Normal & 3 & $(-)$ & 5 & $\begin{array}{l}\text { PPI (first) } \\
\text { Oral steroid (second) }\end{array}$ & Persistence & Normal & 2 & $(-)$ \\
\hline
\end{tabular}

Dysphagia intensity score: 1 = swallowing unhindered and without pain, $2=$ slight retching disappearing spontaneously, $3=$ short periods of obstruction necessitating intervention such as drinking, deep breathing or retching, $4=$ longer-lasting obstruction only removable by vomiting and $5=$ continuous complete obstruction not removable by the patient.

PPI, proton pump inhibitor. 

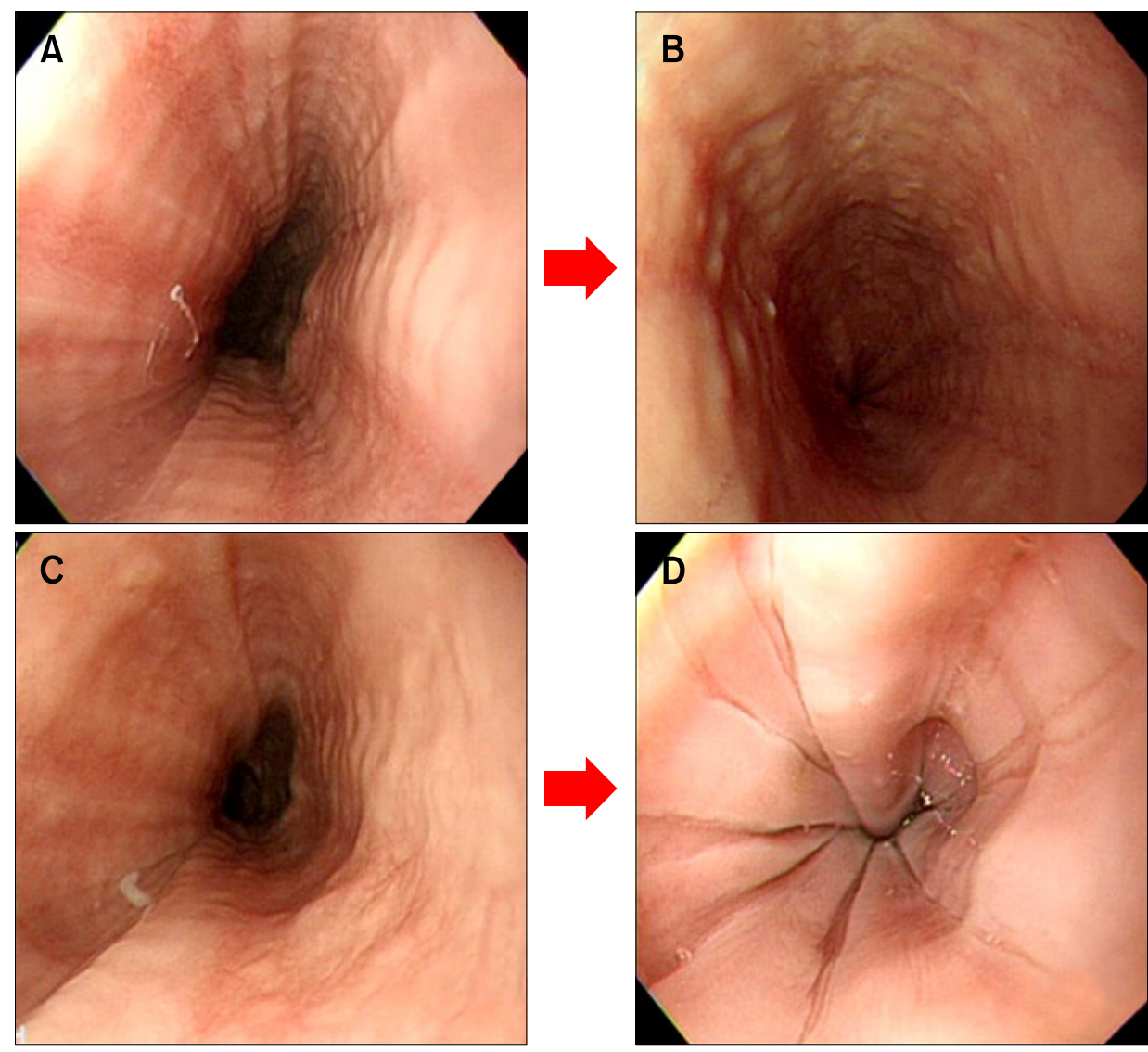

Figure. Endoscopic changes in cases No.2 (A, B) and No.5 (C, D). (A) Initial endoscopic finding was linear furrow, which was maintained at followup endoscopy (after 3 months). (B) Eosinophilia disappeared. (C) Initial finding was linear furrow pattern, and follow-up endoscopy showed a "crepe paper mucosa" pattern (after 25 months). (D) Eosinophilia disappeared.

findings at follow-up endoscopy (Figure).

\section{Discussion}

EoE is a specific disease associated with limited esophageal structure and overt eosinophilic infiltration and has typical symptoms of dysphagia or food impaction. In the past, eosinophilic infiltration of the esophagus was considered as a pathologic condition of reflux esophagitis. ${ }^{11}$ However, in 1993 Attwood et al. ${ }^{2}$ reported that $\mathrm{EoE}$ was distinct from reflux esophagitis and a separate clinical and pathological condition. EoE is known to be related to allergic conditions; although $\mathrm{EoE}$ is a rare disease, its incidence is increased in patients with certain allergic diseases. ${ }^{12,13}$

Asthma is a respiratory disease of bronchial structures with eosinophilic infiltration and inflammation similar to that in EoE. Asthma is a reversible disease in the acute stage, but a chronic clinical course can induce irreversible structural changes in the bronchus. This so-called 'remodelling' can include subepithelial fibrosis and angiogenesis, leading finally to loss of function. ${ }^{14}$

Murine and translational studies support a role for eosino- phils in the development of structural abnormalities observed in the esophageal mucosa. ${ }^{15}$ In patients with EoE, histologic analysis of the esophagus revealed increased fibrous tissue with thickening and alterations in the subepithelial compartments. ${ }^{6}$ This observation was supported by several later studies that also detected oesophageal fibrosis in the subepithelial layer. For example, Aceves et $\mathrm{al}^{16}$ reported subepithelial structural alterations in the esophagus of children with EoE. Specifically, they found esophageal mucosa with significantly increased fibrosis, vascularity, and vascular activation in the subepithelial compartment of all EoE patients. These alterations were not observed in patients who had reflux esophagitis. In contrast to patients with reflux esophagitis and normal controls, children who had EoE demonstrated increased expression of transforming growth factor beta 1 (TGF- $\beta 1$ ) in their esophageal mucosa. TGF- $\beta 1$ plays a crucial role in the irreversible inflammatory process and an increase in TGF- $\beta 1$ expression induces development of remodelling signs. ${ }^{17}$

In our study, baseline values for average age, male/female ratio and personal history of allergic disease were comparable to those in other studies. However, our study had no severe pro- 
gressive cases, such as complete obstruction or long segment obstruction.

Our treatment of EoE involved PPI and/or oral or inhaled corticosteroid. In the previous studies, the goal of the treatment in EoE had not been defined precisely. That is, both symptomatic relief and resolution of inflammation by eosinophils were included as successful treatment outcomes. ${ }^{18}$ The study on treatment of $\mathrm{EoE}$ is still at the stage of clinical trials. Equally, we also did not define the final goal of the treatment in this study. Nonetheless, all patients treated with PPI or corticosteroid showed effective symptom relief, even though some cases relapsed at long term follow-up. In the patients of EoE, PPI treatment is controversial. Typical EoE is defined as 'by the unresponsiveness to PPI.' However, recent study in Japan discovered the PPI-effective EoE. In this study, out of 9 patients who had been on medical care, 5 patients were treated with PPI. The researcher led to a conclusion that EoE which is strictly defined as unresponsiveness to PPI might be rare in Japan. Moreover, other studies suggest that PPI treatment was effective in EoE patients with confirmed acid-suppression. The therapeutic effect of PPI was suggested to involve attenuation of the permeability of the esophageal wall to exogenous allergens and curing of mucosal injury through acid suppression, in addition to an anti-inflammatory effect. ${ }^{19,20}$ On the other hand, we cannot exclude the possibility that the PPI-effectiveness is due to the GERD combined with EoE. The pathologic relationship or overlap between EoE and GERD is yet unclear. ${ }^{21}$ And like in other studies, 2 patients had the reflux esophagitis in our study. ${ }^{22}$

We scored dysphagia according to its intensity. Except for the child, all patients had a dysphagia intensity score below 3 and there was no food impaction. After treatment, the dysphagia symptom was generally improved, but some patients showed recurrence, and some had continued dysphagia symptoms although the eosinophil infiltration was greatly reduced. Endoscopic findings of EoE persisted at follow-up despite treatment. The recurrence and persistence of dysphagia symptoms could be related to the typical endoscopic findings at follow-up, which indicate that irreversible structural changes were induced in response to chronic inflammation due to eosinophil infiltration. Such irreversible structural changes in the esophagus are known to develop in typical eosinophil-induced inflammatory processes such as the 'asthma remodelling pattern.'

There are some limitations in our study. Although it involved 4 medical centers, it included only a small number of cases and the interval time of follow-up endoscopy was not consistent. The method and duration of treatment varied from patient to patient. For example, some patients were treated with PPI, and the duration varied from 4 to 8 weeks. Some were treated with steroid, and the duration also varied from 6 weeks to 7 months. Therefore, a large-scale and prospective study is necessary for validation of the findings of this study.

In summary, our results indicate that treatment of EoE with PPI and/or steroids can improve the symptoms and eosinophil counts, but endoscopic findings typically persisted at follow-up. These results suggest that $\mathrm{EoE}$ is a chronic inflammatory disease with frequent recurrence and must be managed over a long time despite proper treatment.

\section{References}

1. Landres RT, Kuster GG, Strum WB. Eosinophilic esophagitis in a patient with vigorous achalasia. Gastroenterology 1978;74:12981301.

2. Attwood SE, Smyrk TC, Demeester TR, Jones JB. Esophageal eosinophilia with dysphagia. A distinct clinicopathologic syndrome. Dig Dis Sci 1993;38:109-116.

3. Lee KM, Lim HC, Kim JH, Yoon YH, Park HJ, Lee SI. [Clinical implications of endoscopically suspected eosinophilic esophagitis.] Korean J Gastroenterol 2010;56:285-292. [Korean]

4. Kim KH, Chung IH, Kim JH, et al. Analysis of the clinicopathologic features of eosinophilic esophagitis: comparative study with nonobstructive dysphagia. Korean J Gastrointest Endosc 2011;42: 143-151.

5. Croese J, Fairley SK, Masson JW, et al. Clinical and endoscopic features of eosinophilic esophagitis in adults. Gastrointest Endosc 2003;58:516-522.

6. Potter JW, Saeian K, Staff D, et al. Eosinophilic esophagitis in adults: an emerging problem with unique esophageal features. Gastrointest Endosc 2004;59:355-361.

7. Furuta GT, Straumann A. The pathogenesis and management of eosinophilic oesophagitis. Aliment Pharmacol Ther 2006;24:173-182.

8. Furuta GT, Liacouras CA, Collins MH, et al. Eosinophilic esophagitis in children and adults: a systematic review and consensus recommendations for diagnosis and treatment. Gastroenterology 2007; 133:1342-1363.

9. Abe $\mathrm{Y}$, Iijima K, Ohara S, et al. A Japanese case series of 12 patients with esophageal eosinophilia. J Gastroenterol 2011;46:25-30.

10. Straumann A, Spichtin HP, Grize L, Bucher KA, Beglinger C, Simon HU. Natural history of primary eosinophilic esophagitis: a follow-up of 30 adult patients for up to 11.5 years. Gastroenterology 2003;125:1660-1669.

11. Winter HS, Madara JL, Stafford RJ, Grand RJ, Quinlan JE, Goldman H. Intraepithelial eosinophils: a new diagnostic criterion for reflux esophagitis. Gastroenterology 1982;83:818-823.

12. Kapel RC, Miller JK, Torres C, Aksoy S, Lash R, Katzka DA. Eosinophilic esophagitis: a prevalent disease in the United States that affects all age groups. Gastroenterology 2008;134:1316-1321. 
13. Dellon ES, Aderoju A, Woosley JT, Sandler RS, Shaheen NJ. Variability in diagnostic criteria for eosinophilic esophagitis: a systematic review. Am J Gastroenterol 2007;102:2300-2313.

14. Reed CE. The natural history of asthma in adults: the problem of irreversibility. J Allergy Clin Immunol 1999;103:539-547.

15. Mishra A, Hogan SP, Brandt EB, Rothenberg ME. An etiological role for aeroallergens and eosinophils in experimental esophagitis. $\mathrm{J}$ Clin Invest 2001;107:83-90.

16. Aceves SS, Newbury RO, Dohil R, Bastian JF, Broide DH. Esophageal remodeling in pediatric eosinophilic esophagitis. J Allergy Clin Immunol 2007;119:206-212.

17. Cho JY, Miller M, Baek KJ, et al. Immunostimulatory DNA inhibits transforming growth factor-beta expression and airway remodeling. Am J Respir Cell Mol Biol 2004;30:651-661.

18. Rothenberg ME. Biology and treatment of eosinophilic esophagitis.
Gastroenterology 2009;137:1238-1249.

19. De Jonge PJ, Siersema PD, Van Breda SG, et al. Proton pump inhibitor therapy in gastro-oesophageal reflux disease decreases the oesophageal immune response but does not reduce the formation of DNA adducts. Aliment Pharmacol Ther 2008;28:127-136.

20. Krarup AL, Villadsen GE, Mejlgaard E, Olesen SS, Drewes AM, Funch-Jensen P. Acid hypersensitivity in paitents with eosinophilic oesophagitis. Scand J gstroenterol 2010;45:273-281.

21. Sphechler, SJ, Genta, RM, Souza, RF. Thoughts on the complex relationship between gastroeophageal reflux disease and eosinophilic esophagitis. Am J Gastroenterol 2007;102:1301-1306.

22. Remedios M, Campbell C, Jones DM, Kerlin P. Eosinophilic esophgitis in adults: clinical, endoscopic, histologic findings, and respose to treatment with fluticasone proprionate. Gastrointest Endosc 2006;63: $3-12$. 